\title{
A NEW LOOK AT OSTEOGENESIS IMPERFECTA
}

\author{
A CLINICAL, RADIOLOGICAL AND BIOCHEMICAL STUDY OF FORTY-TWO PATIENTS
}

\author{
Robert J. Bauze, Adelaide, Australia, Roger Smith and Martin J. O. Francis, Oxford, England \\ From the Nuffield Departments of Orthopaedic Surgery and Medicine, University of Oxford
}

\begin{abstract}
In a clinical, radiological and biochemical study of forty-two patients from Oxford with osteogenesis imperfecta, it was found that patients could be divided simply into mild, moderate and severe groups according to deformity of long bones. In the severe group (seventeen patients) a family history of affected members was uncommon and fractures began earlier and were more frequent than in the mild group (twenty-two patients); sixteen patients in the severe group had scoliosis and eleven had white sclerae; no patients in the mild group had white sclerae or scoliosis. Radiological examination of the femur showed only minor modelling defects in patients in the mild group, whereas in the severe group five distinct appearances of bone (thin, thick, cystic and buttressed bones, and those with hyperplastic callus) were seen. The polymeric (structural) collagen from skin was unstable to depolymerisation in patients in the severe group, but normal in amount, whereas the reverse was found in the mild group. This division according to long bone deformity may provide a basis for future research more useful than previous classifications.
\end{abstract}

Osteogenesis imperfecta is one of the commonest inherited disorders of connective tissue (McKusick 1972) with which orthopaedic surgeons are concerned, since the main effect of the presumed biochemical abnormality falls on the skeleton. The bones themselves are brittle. In addition they may grow abnormally, fail to remodel, and sometimes produce vast amounts of callus. Little is known of the cause of the bony abnormalities, or of the other features of osteogenesis imperfecta, although it is nearly 200 years since they were first described (Ekman 1788). Terminology remains confused and clinical description often misleading.

This paper attempts to provide a simple and realistic classification of this disorder which may be of help in future research. It is based on a clinical, radiological and biochemical study of forty-two patients seen at the Nuffield Orthopaedic Centre between November 1972 and July 1973. The clinical and radiological aspects are dealt with in some detail whereas the biochemical findings are considered only briefly.

\section{PATIENTS AND METHODS}

All patients were seen in hospital or at their homes. Statements from the patients or their relatives on when fractures began and their estimated total number, and of family history, were used in this study. Each patient was examined in detail. The observations on scleral colour were standardised by using a colour photograph
(Ektachrome film) of the eyes taken alongside a portion of a paint manufacturer's colour chart. The sclerae were graded clinically and from these photographs, according to one of three selected colours called "blue", "intermediate" and "white", by an agreed decision of the authors.

Radiographs were taken of the left femur, and of the spine if there was clinical evidence of scoliosis; when possible these were compared with previous films. It was not considered justifiable to do a more extensive radiological survey because these patients had often had very many radiographs or could expect to need more.

In older patients a blood sample was taken for analysis of plasma calcium, phosphorus, alkaline phosphatase and hydroxyproline fractions. A twenty-fourhour urine sample was collected while the patient was on a low gelatin diet for estimation of total hydroxyproline excretion, by methods previously described (Smith, Russell, Bishop, Woods and Bishop 1973).

Sixteen volunteers provided a skin biopsy for analysis of polymeric (structural) collagen (Francis and Macmillan 1971 ; Francis, Smith and Macmillan 1973).

\section{CLASSIFICATION}

The patients were divided into three clinical groupsmild, moderate and severe-on the basis of deformity of one or more of the long bones, as follows: mild (twentytwo patients) - no long bone deformity; moderate (three

Robert J. Bauze, M.B., F.R.C.S., 301 North Terrace, Adelaide, Australia 5000.

Dr Roger Smith, F.R.C.P., Clinical Reader and Hon. Consultant, Nuffield Department of Clinical Medicine and Orthopaedic Surgery, Nuffield Orthopaedic Centre, Headington, Oxford OX3 7LD, England.

Dr Martin J. O. Francis, Lecturer, Nuffield Department of Orthopaedic Surgery, Nuffield Orthopaedic Centre, Headington, Oxford OX3 7LD, England. 
TABLE I

Clinical findings in forty-two Patients with Osteogenesis IMPERFECTA

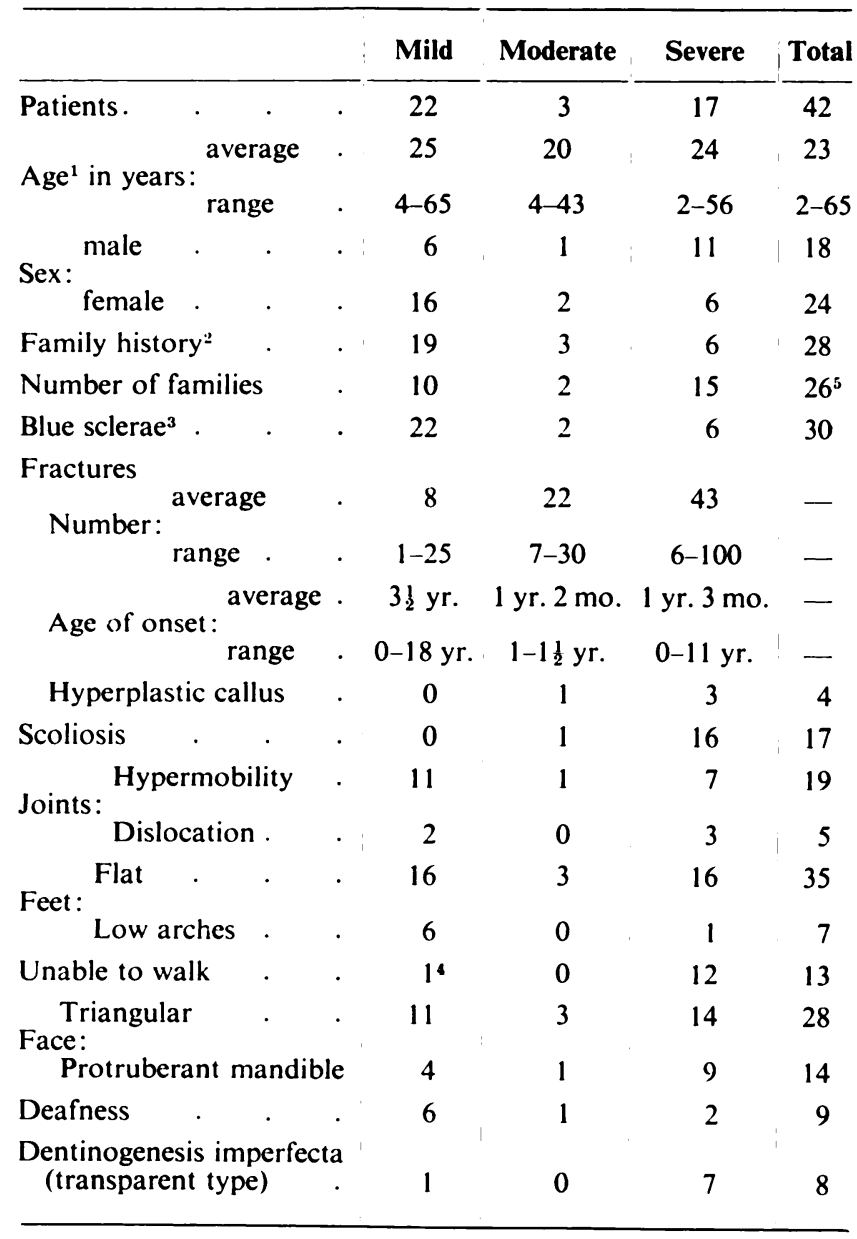

${ }^{1}$ At the time of examination.

2 Parents or siblings.

${ }^{3}$ Includes "intermediate" coloured sclerae (see text).

"See footnote to Table II.

${ }^{5}$ One family common to mild and moderate groups.

\section{TABLE II}

Comparison of the Clinical Findings in Groups of Patients with Mild and Severe Bone Disease

\begin{tabular}{|c|c|c|c|c|}
\hline & & & $\begin{array}{l}\text { Mild } \\
\text { (22 patients) }\end{array}$ & $\begin{array}{l}\text { Severe } \\
\text { (17 patients) }\end{array}$ \\
\hline Family history & . & . & Common & Uncommon \\
\hline Blue sclerae & . & . & All & Few \\
\hline \multicolumn{5}{|l|}{ Fractures: } \\
\hline Number . & . & . & Few & Many \\
\hline Age of onset & . & . & Late & Early \\
\hline Scoliosis & . & . & None & Most \\
\hline Disability & . & . & $\mathrm{Nil}^{1}$ & Severe \\
\hline Deafness & $\cdot \quad \cdot$ & . & Common & Uncommon \\
\hline \multicolumn{2}{|c|}{ Dentinogenesis imperfecta } & . & Uncommon & Common \\
\hline
\end{tabular}

${ }^{1}$ With the exception of one patient in a wheelchair because of paraplegia apparently unrelated to osteogenesis imperfecta (No. 33). patients)-minor long bone deformity; severe (seventeen patients)-severe long bone deformity. The reasons for choosing this method are discussed below.

\section{RESULTS}

\section{CLINICAL FEATURES}

The salient clinical features are shown in Table I. In Table II we have contrasted the groups with mild and severe bone disease; certain aspects of this comparison are dealt with below.

The average age of the patients in mild and severe groups at the time of review was similar. There were more females and more patients with a positive family history in the mild group than in the severe group. Patients in the mild group with blue sclerae tended to come from a few families and had been traced through affected siblings. Cases in the severe group tended to be sporadic.

Fractures-Bony fragility is the sign that usually draws attention to the disease. Figure 1 records each patient with particular reference to the period of life at which fractures occurred, and to the number of fractures.

Age of onset of fractures-This varied widely. In individual cases it did not always indicate the severity of bone disease. In general, the earlier fractures began the more severe the disease. Nine of seventeen patients in the severe group had fractures at birth. However, in four of the severe group fractures began after the age of one year, one at eleven years, while in three of the mild group they first occurred before one year-one of them at birth.

Estimated total number of fractures-Although the overall relation of this feature to severity of bone disease is obvious (the severe group averaged forty-three fractures, the mild group only eight), in individual cases this relationship did not always apply. For example, a woman aged forty-one (Case 28) has had twenty-five fractures but has no long bone deformity and is therefore in our mild group. Another patient (Case 24) in our severe group has had only twelve clinically recognised fractures.

Cessation of fractures-Most patients have continued having fractures throughout adult life.

Long bone deformity-The types of deformity found in the severe group have been well described recently (Albright and Grunt 1971; King and Bobechko 1971) and do not require detailed description. Bowing of one or more of the long bones has particularly been noted.

Spinal deformity-The principal deformity was scoliosis, which was present in seventeen ( 40 per cent) of the fortytwo patients. Sixteen of these seventeen were in the severe group. In the severe group the only patient without scoliosis was the youngest-a girl aged two years (Case 34). Only one patient without severe disease, a forty-twoyear-old woman in the moderate group (Case 3), had scoliosis and this was mild (15 degrees).

The commonest type was a single thoracic curve, and the average curvature was 60 degrees. In some 


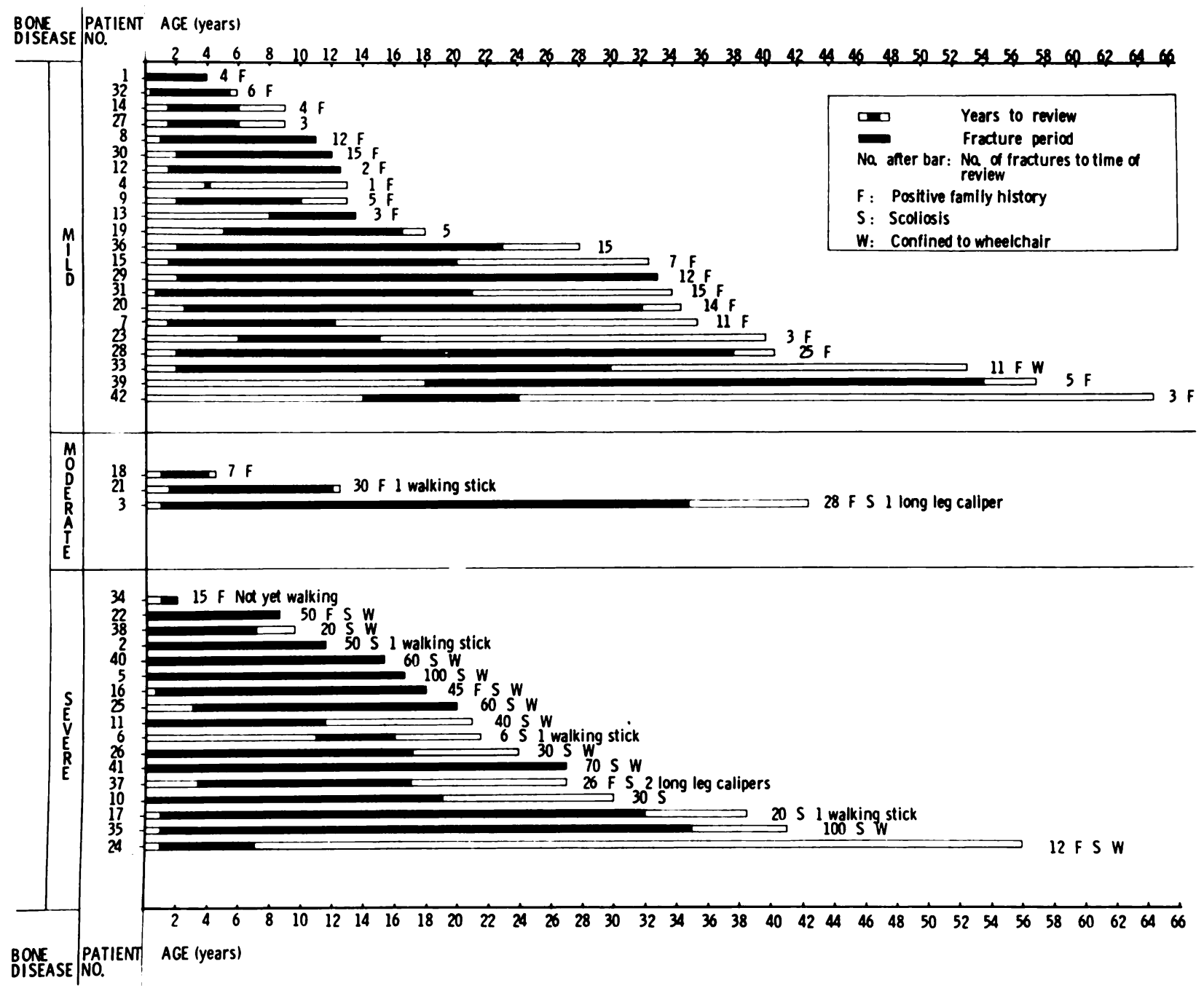

Fig. 1

Forty-two patients with osteogenesis imperfecta. Each bar represents one patient, with age on the horizontal axis. The right-hand end of the bar is the age at the time of our review. The solid part of the bar is the period during their lives when fractures occurred. In most of our patients fractures continued after puberty.

affected individuals the curvature was very severe (up to 130 degrees). The combination of kyphosis and scoliosis added to the unfortunate appearance of the patients with severe disease, giving them a deformed pigeon chest and very short sitting height.

Ligamentous laxity-Forty per cent of patients had excessive mobility of the digits. Almost all the patients had very obvious flat feet, and some had low longitudinal arches, taken as an indication of lax ligaments. Two in the mild group had been attending an orthopaedic clinic for flat feet before the first fracture occurred; blue sclerae were then noted and the diagnosis of osteogenesis imperfecta was made.

Dislocation was uncommon. Only three patients had a dislocated head of radius (regarded as a typical deformity); one had congenital dislocation of the hip; another had recurrent dislocation of the shoulder.

In older patients with severe disease the large joints were very stiff, although excessive mobility was still present in the digits.
Disability-The extent of disability corresponded closely to the three groups (Fig. 1). There were two exceptions. One patient in the mild group (Case 33 ) is a fifty-threeyear-old woman confined to a wheelchair. She is paraplegic in consequence of a neurological complaint not obviously associated with spinal trauma or with osteogenesis imperfecta. In the severe group one patient (Case 10) walks unaided. He is a very determined thirty-yearold-man whose numerous fractures began when he was about six weeks old. He is 130 centimetres tall, has white sclerae and no family history. He works full time as a motor mechanic.

Scleral colour-On the basis of the method described, thirty of the forty-two patients had "blue" or "intermediate" coloured sclerae, and twelve had normal coloured ("white") sclerae. Eleven of the twelve with white sclerae were in the severe group.

The relationship of scleral colour to the severity of disease is shown in Figure 2. Figure 3 records a patient (Case 25) with undoubted severe osteogenesis imperfecta 
whose sclerae are "white". He is a twenty-year-old man whose fractures began when he was about three years old. He has had about sixty fractures and has never walked. Facial appearance and structure-Twenty-eight of the patients had characteristic large frontal bones and a pointed, protuberant mandible.

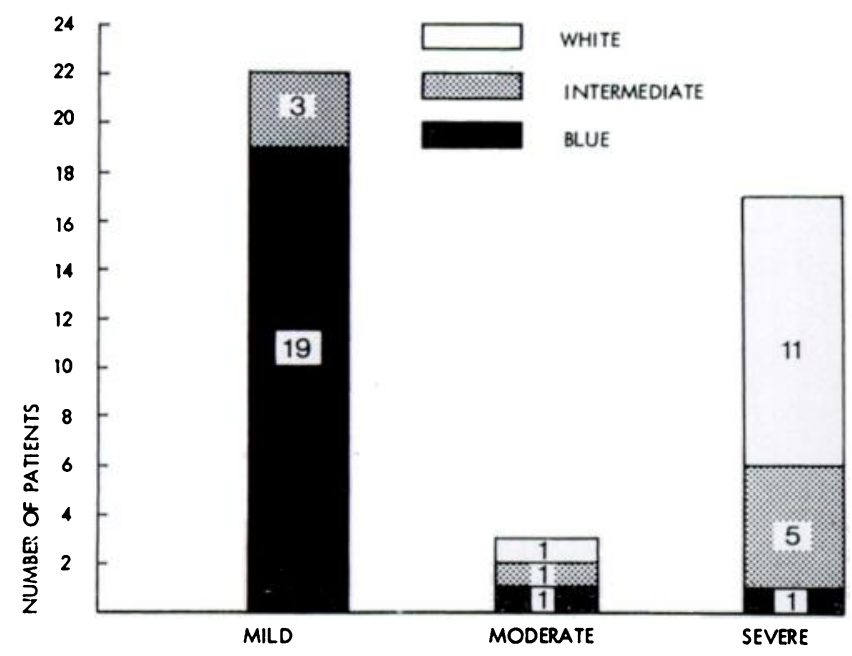

SEVERITY OF BONE DISEASE

FIG. 2

A histogram to show the distribution of scleral colour within the three clinical groups.

Teeth-Dentinogenesis imperfecta of the most obvious, transparent type occurred in eight patients, of whom seven were in the severe group.

Deafness - This first appeared in the third decade in nine patients of the twenty-two who have reached the age of twenty years (six in the mild group, two in the severe and one in the moderate). Stapedectomy had restored hearing in two of these and had failed to do so in one other. Seven had blue or intermediate sclerae. Two had white sclerae.

Voice-A curious squeaky voice and cackling laugh were noted in ten patients, all in the severe group.

\section{RADIOL.OGICAL FEATURES}

Mild group-Figurc 4 shows the appearance of the femur in eleven patients in the mild group. The patient (Case 20) whose radiographs are shown is a man of thirty-four with a family history of the disorder and blue sclerae who has suffered fourteen fractures, none of which was in the femur. The radiograph shows rarefaction. The cortex of the metaphysis and epiphysis is abnormally thin, and there are diagonal lines across the shaft, which we refer to as "feathering", indicated by the arrow. Vertical trabecular lines are prominent. The contour of the bone is abnormal, with a "trumpet" shaped appearance of the metaphysis.

Figure 5 shows a different appearance in the femur of a patient in the mild group. This is the patient in
Case 23, a thirty-nine-year-old man with blue sclerae and a family history of osteogenesis imperfecta. He has had three fractures, none of which were in the femur. In addition to lines of arrested growth and "feathering" in the endosteal surface, the metaphysis is relatively wide, indicating a modelling defect and producing an appearance of the "Erlenmeyer flask" type. This was present in the other eleven of the mild group of patients.

Severe group-Five distinctly different appearances were seen in the patients in this group.

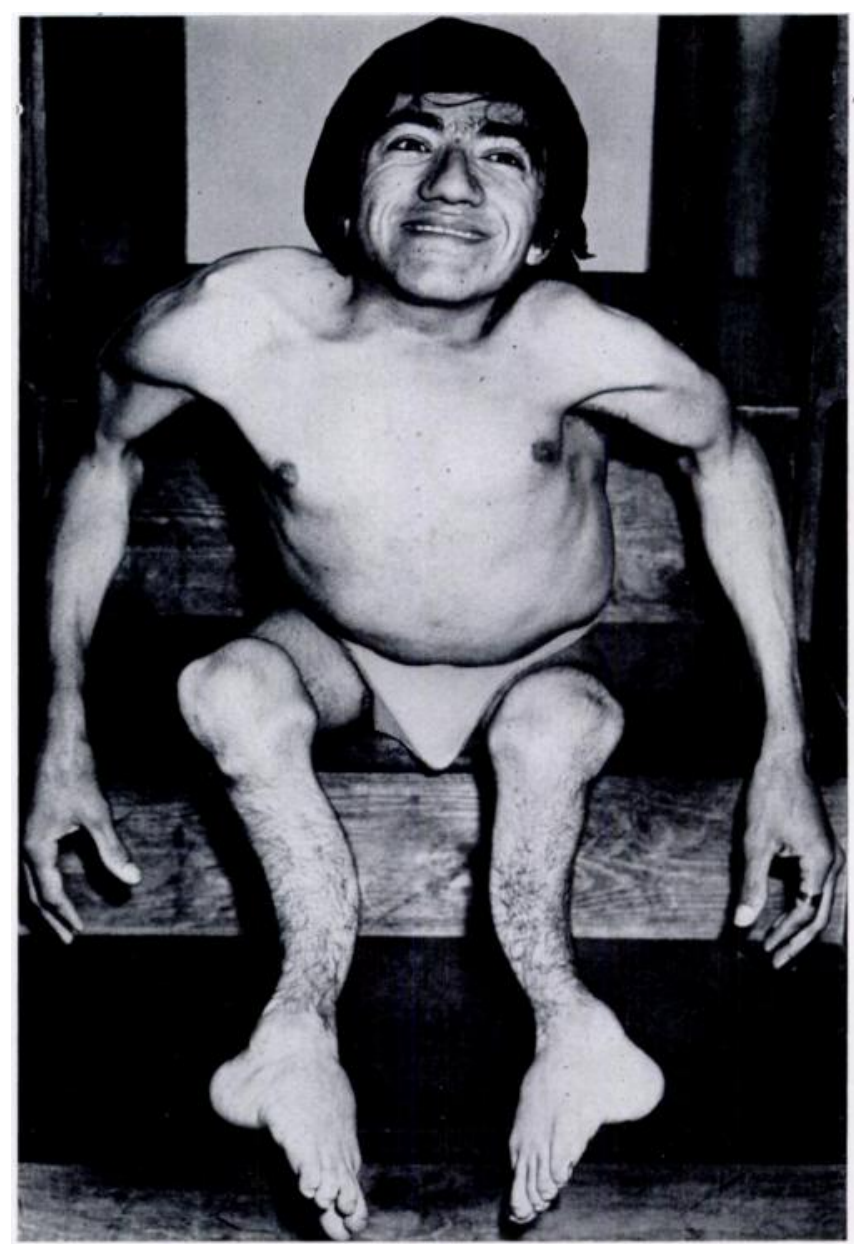

Fig. 3

This patient shows the obvious features of severe osteogenesis imperfecta and has white sclerae (Case 25).

Thin bone appearance-Figure 8 shows the femur of a twenty-four-year-old man (Case 26) with no family history, white sclerae and an estimated thirty fractures. He has never walked. The bone is short, the diaphysis narrowed, the metaphysis is sharply flared but the condyles are of about normal width.

Thick bone appearance-Two examples of this are shown (Figs. 6 and 7). The first (Fig. 6) shows the radiological features of prenatal disease with multiple fractures at birth. The second patient whose radiograph at birth is shown (Fig. 7, Case 38), was first seen by the authors when she was nine years old. At that time she was tiny, severely deformed and had never walked. There was no 


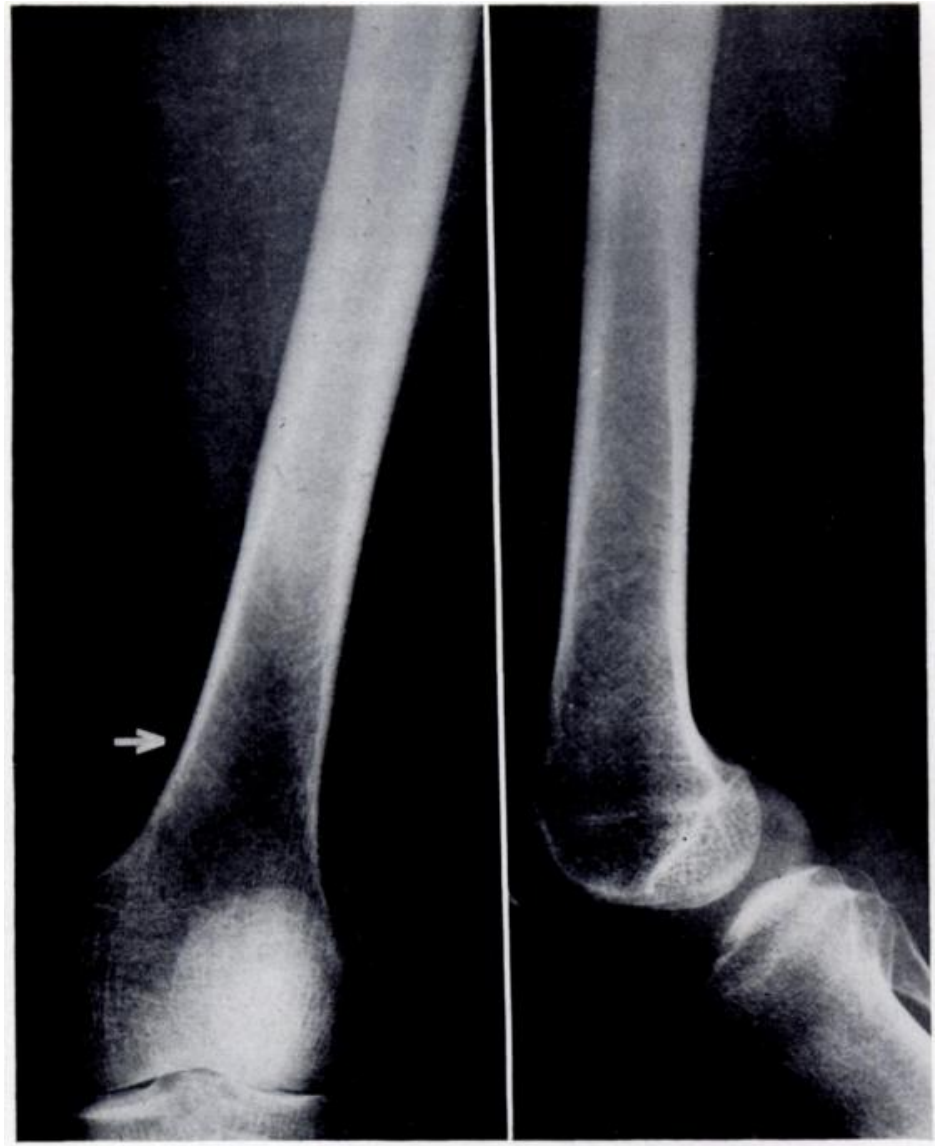

Fig. 4

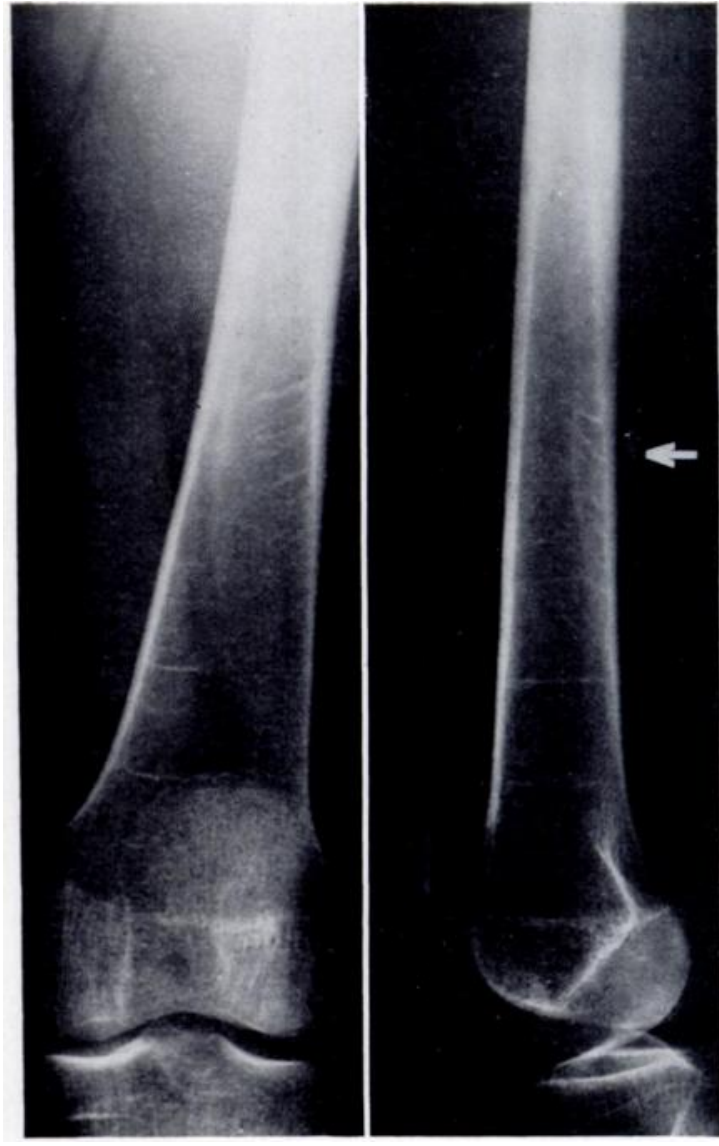

FIG. 5

Radiographs of femora showing changes of mild osteogenesis imperfecta. Figure 4-Thin cortex in the metaphysis and epiphysis and subcortical "feathering" with a trumpet shaped metaphysis. The vertical trabeculae are prominent (Case 20). Figure 5-Metaphysial modelling defect, cortical thinning, prominent Harris lines, vertical trabeculae and "feathering" (Case 23).

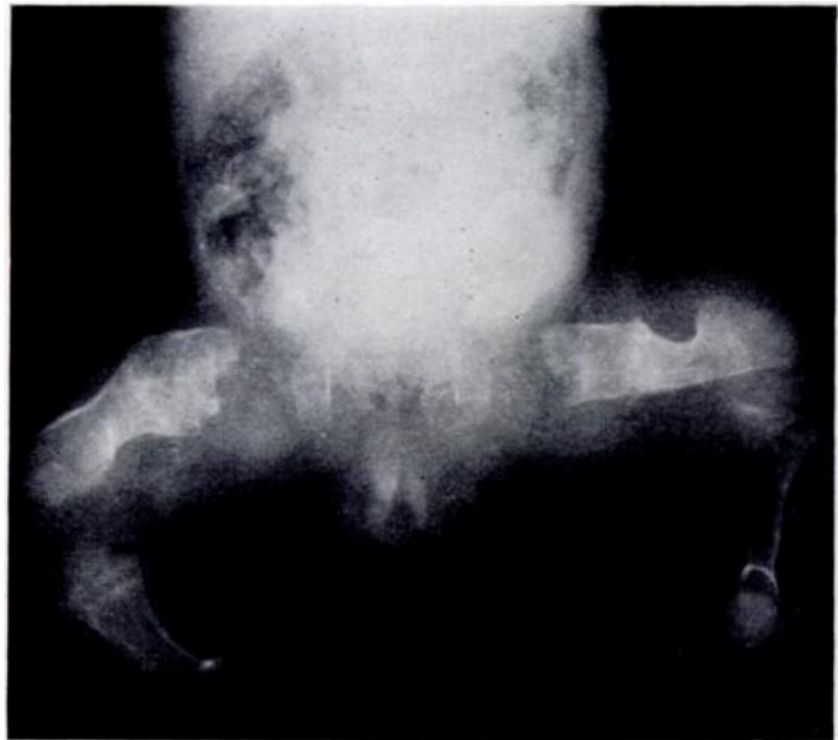

Fig. 6

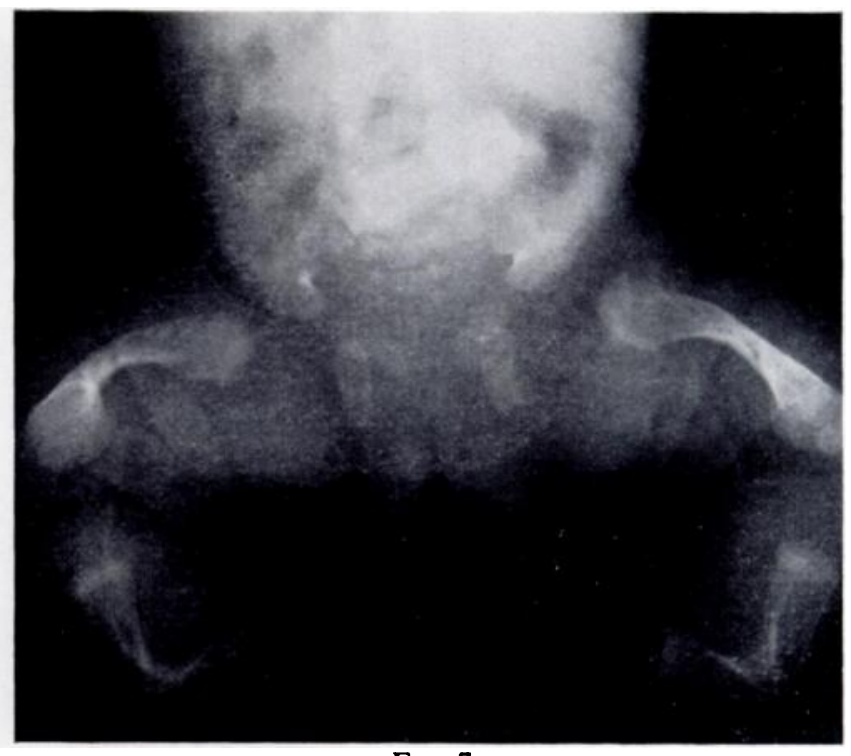

Fig. 7

Severe disease - thick bone appearance. Figure 6-Radiograph taken at birth of a patient (not in the present series) with prenatal fractures. Figure 7-Radiograph taken immediately after birth. Evidence of prenatal disease (Case 38). 


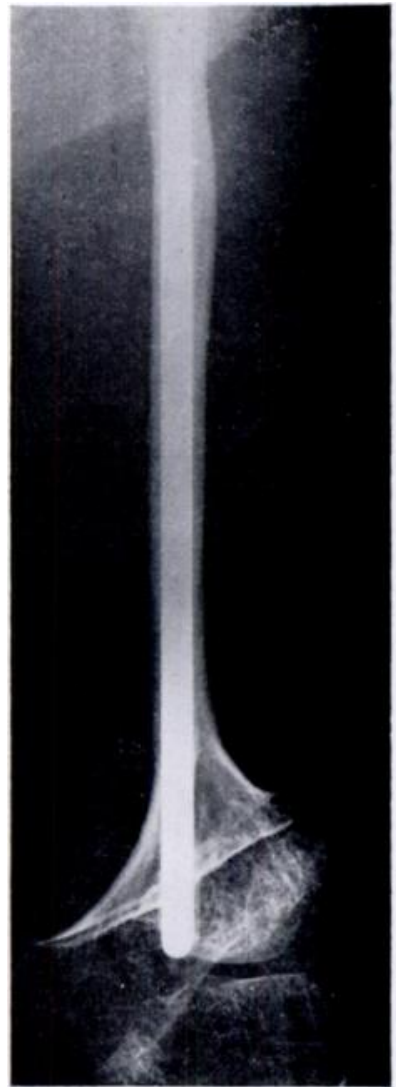

FIG. 8

Severe disease-thin bone appearance (Case 26).

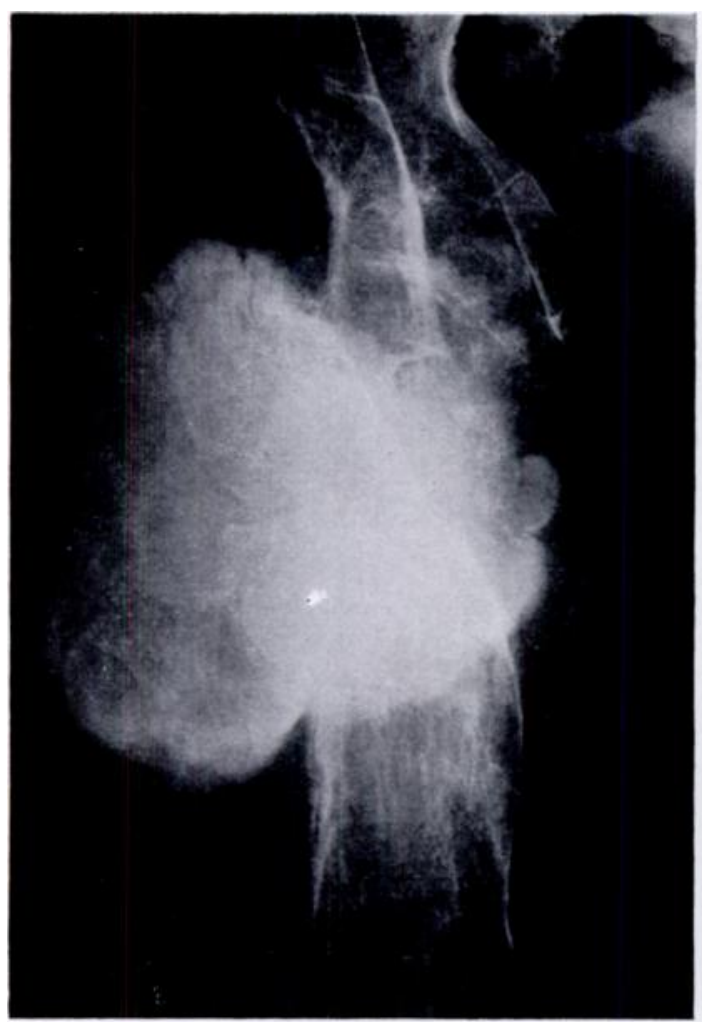

Fig. 10

Severe disease-hyperplastic callus (Case 17). Figure 10-Early callus after fracture. Figure 11-The situation six months later.

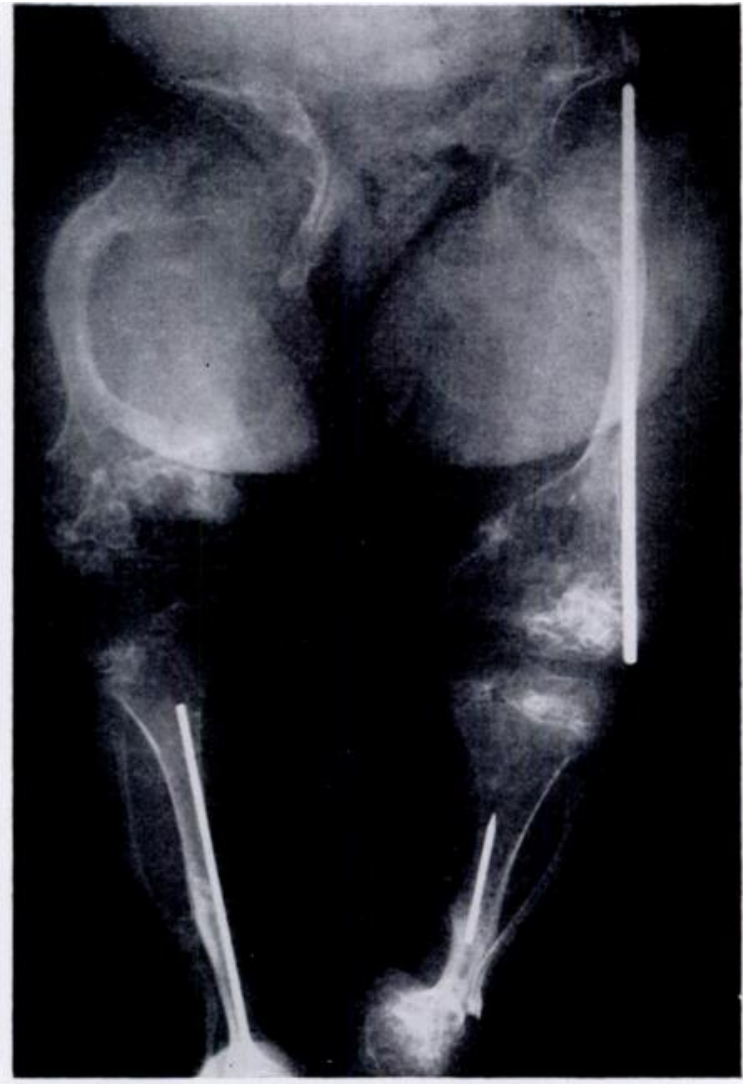

FIG. 9

Severe disease-cystic appearance. At age of 9 years (Case 38).

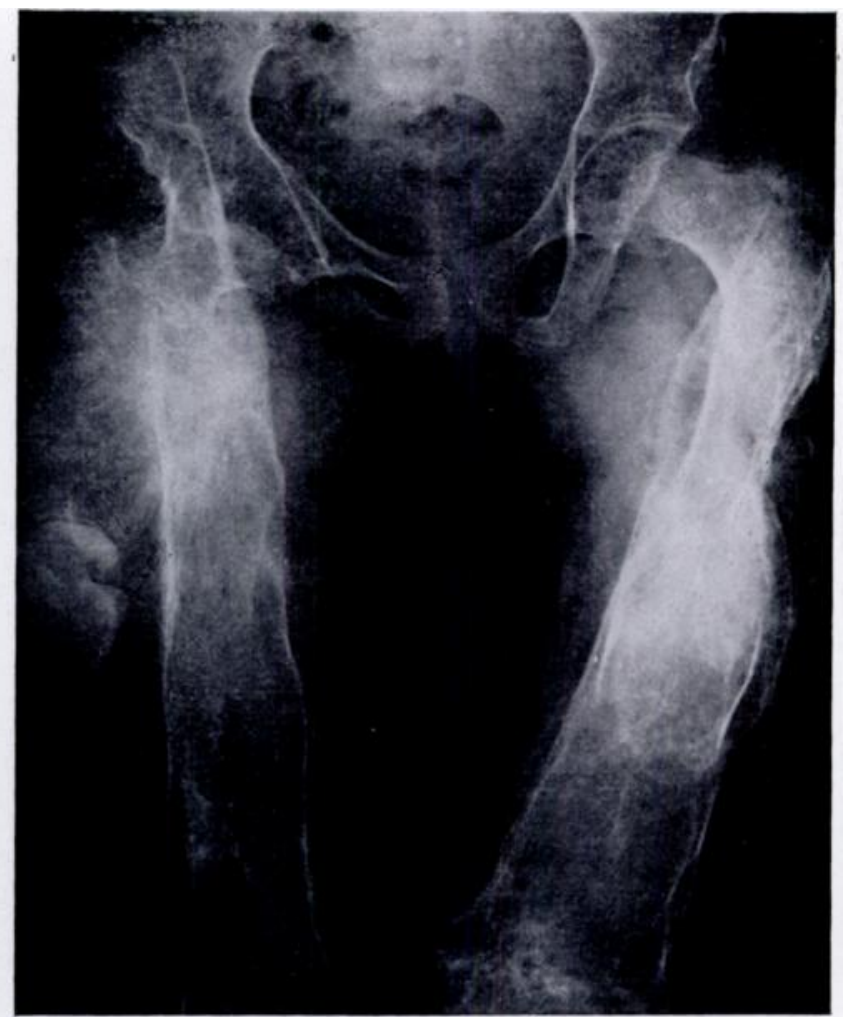

FIG. 11 
family history of osteogenesis imperfecta and the sclerae were of "intermediate" colour.

Cystic appearance-The radiological appearance shown in Figure 9 was seen in five patients. This radiograph is of the same patient (Case 38) as that shown in Figure 7 but was taken when the patient was nine years old, and suggests that-if the child survives-the thick bone type may change to the cystic type. All five patients with this appearance had multiple fractures at birth. At that stage they might have qualified for the "congenita" classification of Looser (1906). None of them had ever walked.

Hyperplastic callus-This appearance was seen in four patients. A thirty-eight-year-old woman (Case 17, Figs. 10 and 11) with no previous family history, and her

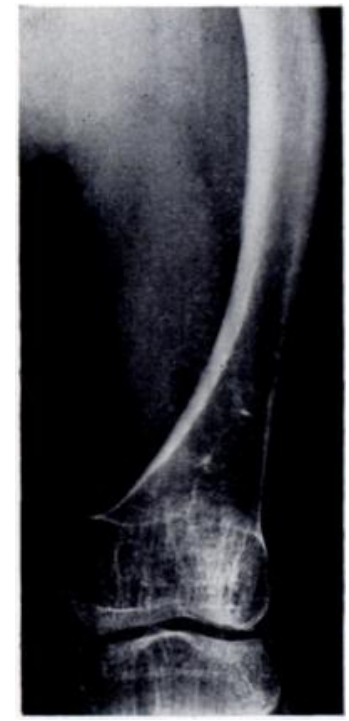

Fig. 12

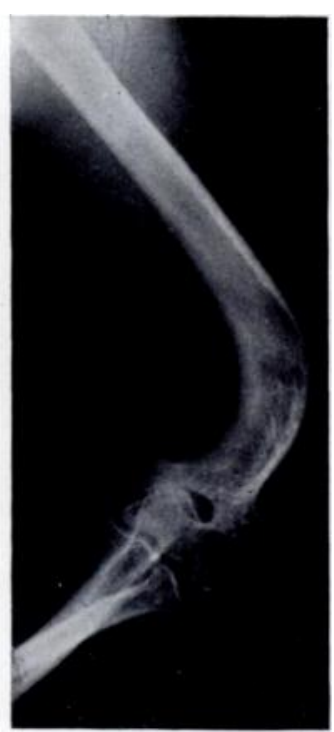

Fig. 13
Severe disease-buttressed bone. Figure 12-Femur of the only patient in the severe group who walks unaided. There is considerable thickening of the diaphysial cortex (Case 10). Figure 13-Humerus of patient who leads a very active life from a wheelchair (Case 26).

four and a half-year-old son (Case 18) developed masses of callus with each fracture as did a forty-one-year-old man (Case 35) with no family history of affection, and his two-year-old daughter (Case 34).

Buttressed bone appearance-This was seen in the long bones of the patients in the "severe" group who had maintained activity and stress through them. Figure 12 shows the femur of the only patient in the "severe" group who could walk unaided. Figure 13 shows the humerus of the patient in Case 26. He is a twenty-four-year-old man who leads an active wheelchair life. The appearance of his humerus, which presumably bears a lot of stress, makes an interesting comparison with that of his femur (Fig. 8), which has never borne weight.

Both buttressing and hyperplastic callus formation may produce apparent thickening of the bone, which is not to be confused with the appearances shown in Figures 6 and 7-the "thick bone type" of Fairbank (1951).
Among the non-specific radiological appearances in our group, triradiate pelvis and "codfish" vertebrae were a common feature. Ossification of radio-ulnar and tibiofibular interosseous membranes was seen in three patients in the "severe" group.

\section{BIOCHEMISTRY}

The mean plasma calcium, phosphorus and alkaline phosphatase in our group of patients showed no significant difference from the normal range. In one adult patient (Case 3) there was an unexpectedly low plasma phosphate-2.2 milligrams per 100 millilitres-and in two adult females with mild disease (Cases 7 and 33) a raised plasma alkaline phosphatase. In eight other patients the alkaline phosphatase showed the normal increase associated with growth (Round 1973). The plasma non-proteinbound hydroxyproline was within the normal range (0.4-2.5 milligrams per litre), as was the protein-bound hydroxyproline ("hyproprotein") (4-10 milligrams per litre). The urinary total hydroxyproline, expressed as milligrams per day, was not significantly different from normal, allowing, where appropriate, for the normal changes with age. Correction for surface area derived from height and weight in the severely affected patient is largely unrealistic.

Analysis of polymeric (structural) collagen of a skin biopsy taken from sixteen volunteers in the group was more fruitful. This fraction, which comprises some 75 per cent of total collagen of normal skin, was extracted by the method of Francis and Macmillan (1971), and then subjected to depolymerisation by enzymes (such as pronase) or cold alkali (Francis, Smith and Macmillan 1973).

In total amounts this structural collagen was normal in those with severe disease (severe long bone deformity), who generally had white sclerae. It was significantly decreased from normal controls in those with mild disease (no long bone deformity) and blue sclerae.

There was a significant decrease in the stability to depolymerisation by cold alkali in the structural collagen of skin from those with severe disease as compared to that from age-matched controls. In those with mild disease the stability of structural collagen of skin was normal. Only two patients (Cases 23 and 33), both with mild disease, had no significant abnormality.

These results will be published in full elsewhere and are discussed only briefly below.

\section{DISCUSSION \\ CLASSIFICATION}

Since Ekman first described the clinical features of osteogenesis imperfecta in 1788 various authors have attempted to classify patients with this disorder. Thus, Looser (1906) 
made the first division into "congenita" and "tarda" forms, and his "congenita" form referred specifically to those patients whose fractures first occurred before birth; affected individuals were either stillborn or died within hours of birth. The remainder with the condition were called "tarda". Despite this division he felt that both types were manifestations of the same underlying disease. Later Seedorff (1949) in his classic study subdivided the tarda group into gravis and levis, which gave three groups or types: Type 1-congenita (as defined by Looser); Type 2-tarda gravis with fractures first occurring at the time of birth or during the first year of life; and Type 3tarda levis, with fractures first occurring after the first year.

The term "congenita" has not always been used in the literature in accordance with Looser's original definition. Not all patients with prenatal fractures die at or near birth and Seedorff suggested that the surviving ones be put into the tarda group. Some authors appear to follow this suggestion, but it seems illogical to class patients with fractures at birth differently according to whether they survive. Further, some writers on the subject (for example, Freda, Vosburgh and Di Liberti 1961) appear to use the words "congenita" and "congenital" synonymously. If used correctly the term congenital would include some patients of Type 2 (those with fractures at birth) as well as all those in the Type 1 group.

Most previous authors, however, agree that there is a spectrum of clinical presentation and that there are no clear clinical distinctions between type and group as previously defined (Herndon 1956; Caniggia, Stuart and Guideri 1958; Smårs 1961; Albright and Grunt 1971; McKusick 1972). In particular the distinction between Types 1 and 2 may be really one of severity of disease, and that between Types 2 and 3 merely an arbitrary point in time-namely, one year of age. Because of the above considerations and because the clinical findings in this group of patients did not correlate well with existing terminology a more simple grouping has been used. In earlier studies of these patients (Smith and Francis 1973) the division into mild and severe bone disease, assessed by age of onset, approximate number of fractures, scoliosis and disability correlated well with blue and white sclerae respectively. Subsequently it was found that the simple criterion of whether or not one or more long bones were bent correlated very well with other aspects of the disorder. Almost the same groups could have been produced by choosing as the criteria features which are secondary to the bone disease such as scoliosis or inability to walk unaided; but "bent bones" or "long bone deformity" appears to be a more fundamental sign of the disease, which may better indicate the underlying pathology. Two patients with minor degrees of malunion following condylar fractures of the humerus are included in the mild group, as are one patient with minor malunion after two Colles's fractures and two further patients with knock knees not associated with fracture.

\section{CLINICAL FEATURES}

Fractures-The types of fracture did not show any unusual features. The group is not large enough and the knowledge of the number of fractures per year or the amount of trauma which caused them not accurate enough to give a valid estimate of the rate of fractures and its relation to increasing age. The impression is that frequency of fracture decreases with age, while the tendency to fracture with less than normal trauma persists, albeit at a low level, throughout life. Fractures continue to occur in many patients in the third and fourth decades (Fig. 1).

Long bone deformity-This is not always related to the number of reported fractures (Fig. 1) nor is it related to malunion of treated fractures. It seems that the bones of patients in the severe group may bend independently of reported fractures or treatment, possibly due to undiagnosed microfractures (King and Bobechko 1971). Thus, for example, the patient in Case 24 reports only twelve fractures but has the classical severe deformities of osteogenesis imperfecta.

Spinal deformity-Scoliosis and kyphosis account for a considerable degree of the deformity seen in the severe group. We agree with King and Bobechko (1971) that the commonest type of scoliosis is a single thoracic curve.

Ligamentous laxity-Excessive mobility of the digits and flat or low-arched feet were the principal evidence of laxity of ligaments. Dislocation of joints was uncommon, and we have no evidence to support the view of Caniggia, Stuart and Guideri (1958) that dislocations, when they occur, are often due to a developmental defect of articular heads.

The stiffness of large joints in older patients with severe disease is inexplicable, but immobilisation by plaster or disuse may contribute to it.

Scleral colour-After brittle bones, blueness of the sclera is the commonest reported characteristic sign of osteogenesis imperfecta, first noted in 1896 by Spurway, then in 1900 by Eddowes. It is generally considered that the blue colour is due to the sclerae being thin and the colour of the vessel-rich choroid showing through. This explanation for the sign was reported by Buchanan (1903) in a patient not noted to have osteogenesis imperfecta. The sclera, which was markedly blue, was thin and contained "fewer than normal fibres" which were however of normal size. Ruedemann (1953) verified this finding in a baby boy with osteogenesis imperfecta who died several hours after birth. Seedorff (1949) said that all 180 of his patients with osteogenesis imperfecta had blue sclerae and that any dispute about this was due to the inexperience of the observer. Other workers disagree and describe cases of the disease with white sclerae (Fairbank 1951; Herndon 1956; King and Bobechko 1971). Some (for instance Caniggia, Ravenni and del Giovane 1961) stated that the later the onset of fracture the lower was the frequency of blue sclerae. This confusion led us to use the colour chart method of assessment to add some degree of objectivity and to help clarify these past observations. 
A constant problem of assessment of scleral colour in osteogenesis imperfecta is the colour range in normal people. Babies and small children under about two years have distinctly blue sclerae. Any statement in the literature of blue sclerae in young children which has been used to support a diagnosis of osteogenesis imperfecta should be treated with caution. Similarly, errors in observation may arise because normal adults often have sclerae with a bluish tinge. It may be that once the diagnosis of osteogenesis imperfecta has been made there is a tendency to convince oneself that the sclerae are abnormally blue, under the impression that this is a constant feature in all patients with this condition.

From the present study we conclude that blue sclerae are a prominent sign in osteogenesis imperfecta but certainly not a constant one. In our older patients with more severe disease and earlier onset of fracture, the sclerae are more likely to be white. Patients with a later onset and less severe disease are likely to have blue sclerae. The blueness of the sclerae need not be uniform and tends to be less marked at the sites of attachment of the external ocular muscles. It was said by some patients with osteogenesis imperfecta and by their parents that the sclerae became paler at about the time the frequency of fractures was decreasing. Further, in our group, parents of three children with osteogenesis imperfecta believed that the sclerae became more blue when the children were about to sustain fractures. Both these observations are difficult to confirm. The relatively large proportion of patients with white sclerae (twelve out of forty-two patients) may suggest a disorder distinct from osteogenesis imperfecta, but all other likely diagnoses (McKusick 1972) have been adequately excluded. It is far more likely that the condition now called osteogenesis imperfecta may eventually be shown to comprise a number of separate disorders. The presence of white sclerae in this condition is not a new observation (Fairbank 1951; Herndon 1956; King and Bobechko 1971), but one which appears to require emphasis and to be associated with severe bone disease.

\section{RADIOLOGICAL FEATURES}

Mild group-In this group the cortical thinning, particularly of the metaphysis and the "feathering" and coarse trabeculae are probably signs of osteoporosis. The prominent Harris lines indicate transient periods of epiphysial disturbance and growth arrest. The absence of resulting deformity after fracture indicates that the bone can remodel adequately, although the "Erlenmeyer flask" appearance in some patients and the "trumpet shape" in others suggests that modelling may not be quite normal. The "Erlenmeyer flask" appearance has recently been noted in cases of homocystinuria (Brenton, Dow, James, Hay and Wynne-Davies 1972), a disease which also has collagen abnormalities (Francis, Smith and Macmillan 1973).
Severe group. Thin bone appearance (Fig. 8)-The narrowness of the diaphysis is presumably due in part to a failure of subperiosteal new bone formation. The bone is short, indicating decreased epiphysial bone growth. The trumpet shape of the metaphysis is possibly due to a modelling defect. The width of the condyles indicates that lateral growth of the epiphysial cartilage is near normal.

Thick bone appearance (Figs. 6 and 7)-The cause of the thickness and distortion of the bones in the prenatal form of the disease is obscure. Multiple intra-uterine fractures and callus formation could be a factor, along with abnormal growth. The shape is abnormal even when there are no obvious fractures.

Cystic appearance (Fig. 9) - This bizarre appearance was seen only in patients who had never walked. The "cysts" are possibly due to gross disturbance of normal stress patterns and the overall shape of the bones in this type indicates once again a modelling disorder.

Hyperplastic callus appearance (Figs. 10 and 11)-In the present series this rare but well-recognised response to fracture appeared to be inherited and occurred in two sets of parent and child. The fact that the abnormal shape does not revert to normal in time indicates a persistent abnormality in the normal processes of bone resorption and remodelling after fracture.

Buttressed bone appearance (Figs. 12 and 13) -This may be interpreted as a response to continued mechanical stress. The bones have been softer than normal and have bent. The cortex appears to be thickened circumferentially in the diaphysis and not only on the concave side of the curve which might be expected. A similar appearance may be seen in some forms of chronic rickets.

\section{BIOCHEMISTRY}

There was no consistent detectable biochemical abnormality in the plasma and urine in the present group of patients. In particular, we were unable to confirm the elevation of the levels of "hypoprotein" reported by Langness and Behnke (1971). This suggests that measurement of the various hydroxyproline fractions in the plasma and urine does not reflect the abnormalities in the structural collagen. The instability of the polymeric collagen in the severe cases implies a defect in cross linking. Grant and Prockop (1972) have recently reviewed the current knowledge of the structure and metabolism of collagen. After collagen molecules are synthesised, intermolecular cross links form tetween adjacent molecules. This progressive cross linking is an essential feature of collagen maturation which gives it its characteristic chemical and physical properties. The chemical nature of some of these cross links is known; in most it remains unknown. It is clear however that a defect in cross linking might have widespread effects in all collagencontaining tissues. Since the overall metabolism of collagen is similar in all tissues, our findings in skin collagen 
can be considered to reflect those in bone and to imply a cross linking defect in the collagen of bone in severe osteogenesis imperfecta (Smith and Francis 1973; Francis, Smith and Macmillan 1973).

\section{PROGNOSIS AND ORTHOPAEDIC MANAGEMENT}

The forty-two patients in the present series show the full clinical and radiological spectrum of this disorder and from them it is possible to make some statement about prognosis and orthopaedic management. Thus, so far as prognosis is concerned, it seems that a baby born with multiple fractures with evidence of prenatal disease will sustain many fractures, will develop severe scoliosis and will be severely dwarfed, and is very unlikely to walk whatever procedure is adopted. Further, scoliosis, however mild, in a child with osteogenesis imperfecta is likely to become severe and to be associated with increasing long bone deformity. It also seems that if long bones bend, either following adequately managed fractures, or without recognised fractures, this indicates a severe outcome. Only eight out of twenty patients with bent bones in the present group can walk, and only two of them without some appliance.

Finally, a patient with a family history of the disorder whose sclerae have remained blue beyond early childhood and whose bones are still straight may subsequently sustain many fractures but is unlikely to have a significant final deformity or disability.

These prognostic statements, if sound, have a bearing on orthopaedic management. Thus, although the standard principles of fracture treatment apply, there may be occasions, as in the most severe forms of the disease, where a wheelchair existence seems inevitable and the prevention of deformity need not be pursued too strenuously.

In those patients in whom elective operations to prevent further fracture and deformity are appropriate, the main discussion arises from the choice of patients for intramedullary fixation, with or without multiple osteotomies (Sofield and Millar 1959; Williams 1965).

The present review suggests that the patients in the mild group (Figs. 4 and 5) do not need this type of treatment. Severely affected patients with thin bones (Fig. 8) or with cystic changes (Fig. 9) may not benefit from it. It should probably be reserved for those who slowly develop bending of a long bone which is of relatively normal width. These operations should be done at any age before the deformity is severe (Williams 1965). If the patient remains active and able to walk it may be possible to reach a "buttressed bone" state, but the eventual result for these severe group patients is in general poor, and it is very likely that any improvement by rodding or multiple osteotomy is only temporary (Tiley and Albright 1973). External splintage may offer protection against direct trauma while providing the stimulus of activity, which appears to be useful in promoting bone development.

\section{PATHOGENESIS}

The idea that osteogenesis imperfecta is caused by a disorder of collagen is not new. Thus in 1900 Eddowes suggested that in patients so affected there was a "want of quality or quantity of the fibrous tissue forming the framework of the various organs of the body", a suggestion which is supported by the present biochemical findings.

There is an association between the clinical, radiological and biochemical findings that appears to separate the mild and severe groups. Thus in the group with long bone deformity the radiographs may show severe modelling abnormalities and the skin collagen may be unstable to depolymerisation, whereas in the mild group moderately normal bones with little defects in modelling are associated with relatively stable structural collagen.

One may wonder whether the clinical and radiological changes result directly from the collagen abnormalities or from the cells which produce it. Certainly histological studies (Follis 1953; Caniggia, Stuart and Guideri 1958; Remigio and Grinvalsky 1970) suggested cellular abnormalities, and Falvo and Bullough (1973) demonstrated that the appearance of the osteoblast was most abnormal in the most severe forms. Further, the production in culture of collagen by fibroblasts from some patients with osteogenesis imperfecta (Brown 1973) may be defective.

It is essential that further laboratory investigation should be related to accurate clinical description. Thus, the main purpose of this paper has been to present primarily the clinical aspects of a combined study on osteogenesis imperfecta, which suggest a simple grouping of patients for which there is clinical, radiological and biochemical evidence and which may form a logical basis for future research.

We are deeply indebted to those surgeons and physicians of the Nuffield Orthopaedic Centre and the Oxford region who allowed us to study their patients; and to the patients themselves for their cooperation. Mr Sydney Nade, now Senior Lecturer in Orthopaedic Surgery in the University of Sydney, contributed greatly to the early part of this study during his tenure of a Girdlestone Scholarship at the Nuffield Orthopaedic Centre. One of us (R. J. B.) was supported by the Girdlestone Scholarship of the Nuffield Orthopaedic Centre Trust. This work was supported by grants from the Wellcome Trust to R. S. and from the Medical Research Council to M. J. O. F.

\section{REFERENCES}

Albright, J. A., and Grunt, J. A. (1971) Studies of patients with osteogenesis imperfecta. Journal of Bone and Joint Surgery, 53-A, 1415-1425. Brenton, D. P., Dow, C. J., James, J. I. P., Hay, R. L., and Wynne-Davies, R. (1972) Homocystinuria and Marfan's syndrome. Journal of Bone and Joint Surgery, 54-B, 277-298. 
Brown, D. M. (1973) Collagen metabolism in fibroblasts from patients with osteogenesis imperfecta. In Clinical Aspects of Metabolic Bone Disease, pp. 303-307. Edited by B. Frame, A. M. Parfitt, and H. Duncan. Amsterdam: Excerpta Medica.

Buchanan, L. (1903) Case of congenital maldevelopment of the cornea and sclerotic. Transactions of the Ophthalmological Society of the United Kingdom, 23, 267-269.

Caniggia, A., Ravenni, G., and del Giovane, L. (1961) On the pathogenesis of fragilitas ossium hereditaria. Panminerva Medica, 3, 67-72.

Caniggia, A., Stuart, C., and Guideri, R. (1958) Fragilitas ossium hereditaria tarda: Ekman-Lobstein disease. Acta medica Scandinavica, Supplementum 340 .

Eddowes, A. (1900) Dark sclerotics and fragilitas ossium. British Medical Journal, 2, 222.

Ekman, O. J. (1788) Descriptio et Casus Aliquot Osteomalaciae. Upsaliae: J. F. Edman.

Fairbank, Sir H. A. T. (1951) An Atlas of General Affections of the Skeleton. Edinburgh and London: E. \& S. Livingstone Ltd.

Falvo, K. A., and Bullough, P. G. (1973) Osteogenesis imperfecta: A histometric analysis. Journal of Bone and Joint Surgery, 55-A, 275-286.

Follis, R. H., Jun. (1953) Histochemical studies on cartilage and bone. III. Osteogenesis imperfecta. Bulletin of the Johns Hopkins Hospital, 93, 386-391.

Follis, R. H., Jun., and Park, E. A. (1952) Some observations on bone growth, with particular respect to zones and transverse lines of increased density in the metaphysis. American Journal of Roentgenology, Radium Therapy and Nuclear Medicine, 68, 709-724.

Francis, M. J. O., and Macmillan, D. C. (1971) The extraction of polymeric collagen from biopsies of human skin. Biochimica et Biophysica Acta, 251, 236-245.

Francis, M. J. O., Smith, R., and Macmillan, D. C. (1973) Polymeric collagen of skin in normal subjects and in patients with inherited connective tissue disorders. Clinical Science, 44, 429-438.

Freda, V. J., Vosburgh, G. J., and Di Liberti, C. (1961) Osteogenesis imperfecta congenita: a presentation of 16 cases and review of the literature. Obstetrics and Gynecology, 18, 535-547.

Grant, M. E., and Prockop, D. J. (1972) The biosynthesis of collagen. New England Journal of Medicine, 286, 194-199, 242-249, 291-300.

Herndon, C. N. (1956) Osteogenesis imperfecta: some clinical and genetic considerations. Clinical Orthopaedics, 8, $132-141$.

Key, J. A. (1926) Brittle bones and blue sclera; hereditary hypoplasia of the mesenchyme. Archives of Surgery, 13, 523-567.

King, J. D., and Bobechko, W. P. (1971) Osteogenesis imperfecta. Journal of Bone and Joint Surgery, 53-B, 72-89.

Langness, U., and Behnke, H. (1971) Collagen metabolites in plasma and urine in osteogenesis imperfecta. Metabolism, $20,456-463$.

Looser, E. (1906) Zur kenntnis der Osteogenesis imperfecta congenita und tarda (sogenannte idiopathische Osteopsathyrosis). Mitteilungen aus den Grenzgebieten der Medizin und Chirurgie, 15, 161-207.

McKusick, V. A. (1972) Heritable Disorders of Connective Tissue. Fourth edition. St Louis: C. V. Mosby.

Remigio, P. A., and Grinvalsky, H. T. (1970) Osteogenesis imperfecta congenita. Association with conspicuous extraskeletal connective tissue dysplasia. American Journal of Diseases of Children, 119, 524-528.

Round, J. M. (1973) Plasma calcium, magnesium, phosphorus and alkaline phosphatase levels in normal British schoolchildren. British Medical Journal, 3, 137-140.

Ruedemann, A. D., Jun. (1953) Osteogenesis imperfecta congenita and blue sclerotics. A. M. A. Archives of Ophthalmology, N.S. 49, 6-16.

Seedorff, K. S. (1949) Osteogenesis imperfecta. A study of clinical features and heredity based on 55 Danish families comprising 180 affected members. Opera ex Domo Biologiae Hereditariae Humanae Universitatis Hafniensis, 20, 1-229. Århus: Universitetsforlaget.

Smårs, G. (1961) Osteogenesis Imperfecta in Sweden: Clinical, Genetic, Epidemiological and Socio-medical Aspects. Stockholm : Svenska Bokförlaget.

Smith, R., and Francis, M. J. O. (1973) Evidence for an abnormality of collagen in osteogenesis imperfecta (Abstract). Quarterly Journal of Medicine, 42, 833-834.

Smith, R., Russell, R. G. G., Bishop, M. C., Woods, C. G., and Bishop, M. (1973) Paget's disease of bone. Experience with a diphosphonate (disodium etridronate) in treatment. Quarterly Journal of Medicine, 42, 235-254.

Sofield, H. A., and Millar, E. A. (1959) Fragmentation, realignment, and intramedullary rod fixation of deformities of the long bones in children. Journal of Bone and Joint Surgery, 41-A, 1371-1391.

Spurway, J. (1896) Hereditary tendency to fracture. British Medical Journal, 2, 844.

Tiley, F., and Albright, J. A. (1973) Osteogenesis imperfecta: treatment by multiple osteotomy and intramedullary rod insertion. Journal of Bone and Joint Surgery, 55-A, 701-713.

Williams, P. F. (1965) Fragmentation and rodding in osteogenesis imperfecta. Journal of Bone and Joint Surgery, 47-B, 23-31. 